\title{
Fire incidents involving regulators used in portable oxygen systems
}

\author{
F Washenitz II, J Stoltzfus, B Newton, L Kubinski
}

\begin{abstract}
Objectives-To address the causes and prevention of fire incidents involving aluminum bodied oxygen regulators used by firefighters or emergency medical technicians.

Methods-The National Institute for Occupational Safety and Health, the United States Food and Drug Administration, and an independent forensic investigator examined several incidents involving injury to firefighters and emergency medical technicians to determine why regulators in these incidents flashed.

Results-Data and test results from investigations revealed that aluminum was a contributing factor, and there were a number of safe handling techniques which firefighters and emergency medical technicians could use to reduce the risk of regulator fires. A provisional test method was proposed by the American Society for Testing and materials (ASTM) in late 2000 to identify designs that would have a propensity for flashing. Results of the test method show good correlation with actual fire incidents.

Conclusion-Development of the ASTM standard and associated testing will be helpful to oxygen regulator designers to design safer oxygen regulator systems. As well, there are a number of additional safe handling procedures that firefighters and emergency medical technicians can follow to reduce the risk of a regulator fire. (Injury Prevention 2001;7(Suppl I):i34-37)
\end{abstract}

Keywords: oxygen regulator fire; firefighter; emergency service; occupational injury

NASA White Sand

Test Facility, Las

Cruces, New Mexico

J Stoltzfus

Wendell Hull \&

Associates, Las

Cruces, New Mexico

B Newton

L\&M

Technologies/White

Sands Test Facility, Las

Cruces, New Mexico

L Kubinski

Correspondence to: Frank Washenitz II, Safety and Occupational Health Specialist, Fire Fighter Investigation Team, NIOSH, Division of Safety Research, M/S H-1900, 1095 Willowdale Road, Morgantown, WV 26505-2888, USA fbw0@cdc.gov designs. Over the past several years there have been reports of portable oxygen systems emitting fire, for example flashing, and causing injuries to firefighters and emergency medical technicians. Investigation of these incidents was conducted by the National Institute for Occupational Safety and Health (NIOSH), the

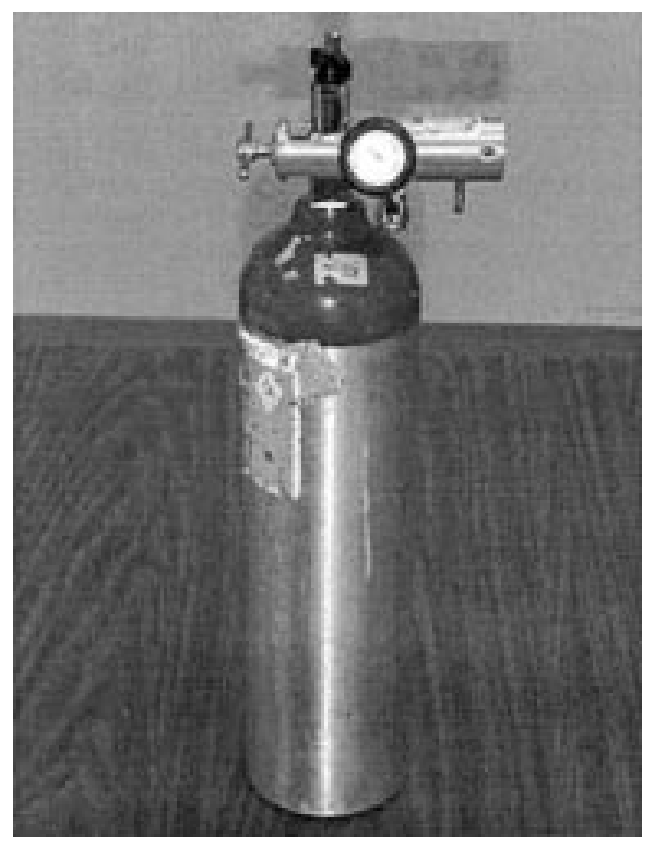

Figure 1 Typical D size cylinder with regulator attached.

United States Food and Drug Administration (FDA), and an independent forensic investigator to determine causes for these regulators to flash.

\section{Recent fire incidents}

The NIOSH Fire Fighter Fatality Investigation and Prevention Program was established in November 1997 with the goal of determining factors that cause or contribute to firefighter deaths suffered in the line of duty. NIOSH was informed by both the International Association of Fire Fighters (IAFF) and the FDA of at least 11 different fire incidents that occurred during the past five years involving aluminum bodied oxygen regulators used by firefighters or emergency medical technicians, 10 of which involved serious injuries. ${ }^{1}$ In July 1998, the IAFF requested that $\mathrm{NIOSH}$ investigate the circumstances surrounding an oxygen regulator fire incident which resulted in the severe injury of a firefighter. This incident, as well as two others investigated by $\mathrm{NIOSH}$, is described below.

\section{Case reports}

\section{CASE 1}

June 1998, a male firefighter in Florid was severely burned when an oxygen regulator flashed during a routine equipment inspection. ${ }^{2}$ Department procedures required the oxygen cylinder post valve be opened, the cylinder pressure verified to be sufficiently full 
for service, the cylinder post valve be closed, and the oxygen remaining in the regulator be released. As the firefighter lifted the oxygen cylinder from the airway supply bag and opened the oxygen post valve, the system immediately flashed, releasing two 4 foot flames from the regulator. His clothing ignited from the waist up, and two on-duty firefighters who witnessed the incident used a garden hose to extinguish the flames. The firefighter received first, second, and third degree burns over $36 \%$ of his body. He was transported to a local trauma center and later airlifted to a burn center.

CASE 2

In South Carolina on 27 August 1998, a female emergency medical technician was severely burned while performing a routine ambulance changeover that required an equipment inspection and restocking of equipment, supplies, and oxygen cylinders. ${ }^{3}$ She removed the bag that housed the oxygen resuscitator from its storage compartment and made three attempts to open the post valve to charge the regulator. Experiencing difficulties because the valve was tightly closed, she braced herself on the step of the patient compartment door and placed the cylinder against her leg and on the step to gain extra leverage to open the post valve.

On the fourth attempt, the regulator charged and immediately flashed, emitting a white fireball. The technician pushed the regulator and cylinder inside the patient compartment as her clothes caught fire from the waist down. She ran into the station bay where she was immediately doused with water by other on-duty emergency medical technicians. The corporal on duty called the fire department and another ambulance, then exited the office to retrieve supplies from the emergency medical technician's ambulance only to find it fully engulfed in flames. Approximately four minutes later the fire department and ambulance arrived. The fire was extinguished, and the victim was transported to a local hospital with burns to approximately $25 \%$ of her upper and lower extremities.

CASE 3

In Nevada on 25 January 1999, a male firefighter received first and second degree burns when an aluminum oxygen regulator caught fire. ${ }^{4}$ As part of the weekly equipment inspection on his assigned engine, he was to remove the oxygen airway supply bag and check the oxygen pressure in the cylinder. Department procedures were similar to those reported in case 1 . The firefighter removed the airway supply bag from the medical compartment, placed the upper half on a shelf at the rear of the engine and the bottom part against his stomach, and began to check the cylinder pressure. The cylinder had been placed in the bag so that the regulator was pointed away from him as he began to charge the regulator.

Upon opening the post valve, the regulator made a loud popping sound and emitted a ball of fire, which quickly spread to the airway supply bag. The firefighter dropped the supply bag and ran into the station bay, where he was met by other firefighters who began treating his injuries. As the regulator continued to burn, the post valve sheared off the cylinder, causing a second flash of fire. The post valve and regulator self extinguished as the medical crews from nearby stations arrived to assist the injured firefighter. $\mathrm{He}$ was transported to a nearby trauma center and sustained first and second degree burns to his head, arms, and hands.

\section{Incident investigations}

The regulator involved in case 1 in Florida had been retrofitted according to the manufacturer's specifications because that particular model had been involved in several fires during the previous three years. The retrofit involved replacing the original filter with a sintered bronze inlet filter and affixing a warning sticker on the regulator that read:

"WARNING: 1. The introduction of contaminates [sic] and hydrocarbon substances into the regulator may cause combustion; 2. Open the cylinder post valve slowly. The sudden inrush of oxygen into the regulator may cause combustion if contaminates [sic] are present". ${ }^{5}$

Independent testing and review of the incident revealed the most probable ignition mechanism was particle impact on the filter during the initial oxygen flow transient (a temporarily unstable oxygen flow) after the firefighter opened the cylinder valve. This ignition led to the burning of the regulator's aluminum body, which caused the flash. Particle impact ignition occurs when a metallic particle contained in the oxygen flow contacts a rigid surface and ignites, which then promotes ignition of the surrounding material. Particle impact has been shown to be one of the most efficient mechanisms for directly igniting metallic components in a high pressure oxygen environment.

In case 2 in South Carolina, the origin of fire could not be isolated with certainty because of extreme damage to the regulator's component parts. However, the melt-flow patterns and propagation paths were consistent with an origin either at the cylinder's valve seat or in the high pressure section of the regulator. Because of the presence of a gauge protector (that blocked the regulator vent ports), the propagation patterns and blowback condition (burning in a backwards direction into the cylinder) would have been expected for initial ignition at either location. Considering the extreme flammability of aluminum under these service conditions, the combustion event would be strongly dominated by aluminum ignition in the regulator in the very early stages of the fire.

Cylinder valve seat ignition caused by frictional interaction with the metallic nozzle, or particle impact ignition against the regulator's stainless steel screen, were the most likely ignition mechanisms. Multiple ignition mechanisms are active in normal oxygen systems, and several of these have been associated with regulator fires with promoted ignition of the aluminum body. This regulator fire was 
considered to be unique when compared to the previous regulator fires because its extreme severity probably resulted from the presence of the gauge protector. This fire represented a new category of oxygen regulator fire that had not previously been observed.

The regulator involved in the incident in case 3 in Nevada was a full bodied aluminum regulator with aluminum exposed to high pressure oxygen throughout the flow path. The same regulator model had been involved in several incidents in the past, including the Florida incident, and had been recalled by the manufacturer to replace a stainless steel screen, located under the inlet nozzle, with a sintered bronze inlet filter. The manufacturer had provided the fire department with a retrofit kit that contained a sintered bronze inlet filter, an inlet screw, and a sticker to be placed on the retrofitted regulator to identify that it had been retrofitted. The regulator involved in this incident had been retrofitted with the kit supplied by the manufacturer. Since this incident, the manufacturer voluntarily recalled all regulators of the same model and offered its customers trade-ins of the aluminum regulators for credit towards the purchase of a brass regulator. ${ }^{5}$

As a result of these and other fire incidents, NIOSH and the FDA issued a joint public health advisory in February 1999 regarding explosions and fires in aluminum oxygen regulators. It provided the following statement as background:

"Most oxygen regulators are made of brass or aluminum. Aluminum and its alloys are more likely to ignite than brass. In standard tests, aluminum can burn vigorously at pressures as low as 25 pounds per square inch (psi), while brass does not burn at pressures below 10000 psi. Although there are rare instances of fires in brass oxygen regulators, they have a long history of safe use and are believed to be safer than aluminum oxygen regulators for use with high pressure compressed oxygen. FDA has no reports of fire or explosion with aluminum oxygen regulators used in low pressure systems (for example, piped distribution to wall mounted supply taps at $<50$ psi)". ${ }^{1}$

The advisory also provided safe handling procedures for oxygen systems and recommended that oxygen regulators which contain any aluminum exposed to high pressure oxygen, be replaced with regulators made of brass. At the time of this advisory, the regulator manufacturer involved in these incidents had issued an interim measure wherein they would replace internal high pressure aluminum components with brass components in all models manufactured.

\section{The solution}

NIOSH and the FDA contacted the National Aeronautics and Space Administration White Sands Testing Facility (NASA) to see if it could, with its long history of oxygen testing for the nation's space program and its association with American Society for Testing and Materials (ASTM) oxygen safety courses, help solve this problem.
As oxygen regulators used in this application are a pharmaceutical delivery device, the FDA has the authority to mandate brass as the only material from which these regulators can be constructed. This, of course, would severely limit the choices available to oxygen regulator designers, and for that reason NASA brought the issue to ASTM's G-4 Committee for discussion. The committee represents a cross section of industry and government engineers and scientists who have experience with developing test methods and practices regarding the flammability and sensitivity of materials in oxygen enriched atmospheres.

At its March 1999 meeting, the committee decided to accept the challenge of designing a test method that would subject oxygen regulators to conditions found in actual use applications under which regulator fires had occurred. Ultimately it was decided that the provisional standard would involve two phases of testing. Phase 1 would evaluate the ignition resistance of the regulator design to heat from oxygen pressure shocks and would follow an already published method described in International Organization for Standardization $10524 .^{6}$ Phase 2 would involve using an ignition "pill" consisting of nylon, aluminum, iron, and possibly a hydrocarbon contaminant, which would be representative of the kinds of contaminants found in oxygen cylinders and regulators during actual service. This ignition "pill" would be placed upstream of the filter typically found in the inlet nozzle of most oxygen regulators.

Although the first phase of this test was considered by some committee members to be a sufficient method to determine the ignition sensitivity and fault tolerance of a particular oxygen regulator, it was demonstrated through anecdotal evidence and test results that the method did not accurately represent a contaminated regulator, and the second test phase would be needed. During the next 18 months, a workable ignition "pill" for phase 2 was developed along with text for a provisional ASTM standard.

The provisional standard was accepted by the committee and became available to the oxygen regulator community in December $2000 .^{7}$ Figure 2 illustrates how results of the phase 2 test duplicate what is found in actual regulator fires.
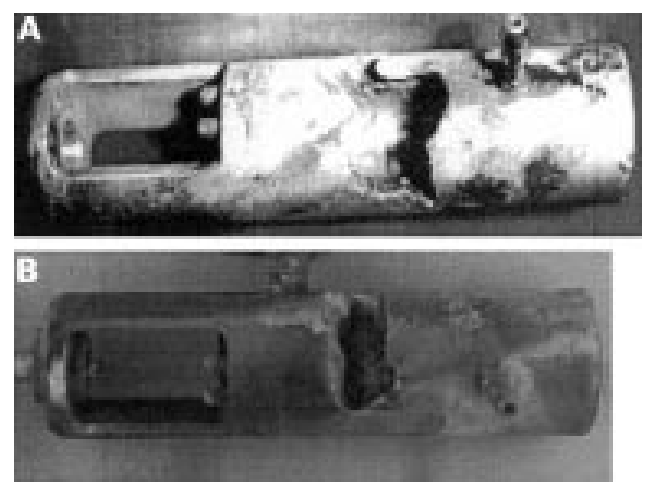

Figure 2 Pictures of $(A)$ oxygen regulator after actual fire and $(B)$ after phase 2 testing. 
The ASTM G-4 committee has two years to validate the test method with round robin testing and bring it to a full consensus standard. This testing is currently in progress under the guidance of G-4 members at NASA.

\section{FDA/NIOSH recommendations}

Based on investigations and available test data, FDA/NIOSH recommended the material in the high pressure section of an oxygen regulator be comparable to or equivalent to brass. ${ }^{1-4}$ In addition, NIOSH concluded that fire departments should implement the following procedures for working with portable oxygen systems to reduce the occurrence of similar incidents.

- During maintenance and inspection procedures, place the cylinder in an upright position with the post valve pointed away from the operator. Open then close the post valve before attaching to the cylinder.

- When opening a cylinder post valve with the regulator attached, open slowly and point away from self and other people.

- Train firefighters in safe handling procedures of portable oxygen systems.

- Store oxygen cylinders and regulators in a cool area free of dirt, oils, and grease.

- Locate oxygen filling stations and maintenance areas in a locked, air conditioned room that is clean and free of dirt, oils, and grease.

- Install added components, such as gauge guards, so they do not block regulator vent holes.

- Ensure that manufacturers provide a warning that clearly indicates that the vent ports on the regulator should not be occluded.
Implications for prevention

The publication of NIOSH investigative reports, the joint FDA/NIOSH public health advisory, and subsequent development of the ASTM standard and associated testing, demonstrate a significant effort to enhance the safety of firefighters and emergency medical services personnel. The ASTM G-4 committee is working diligently with regulator manufacturers to ensure they provide safe designs. ASTM G-4 technical and professional training courses are available for users to prevent hazards associated with oxygen use. Information about these courses can be obtained at www.astm.org. NIOSH and the FDA have also produced a training video on safe handling of oxygen systems. ${ }^{8}$ The goal of these collective efforts is to prevent future injuries to firefighters and emergency medical technicians who use oxygen systems in their day-to-day activities.

1 Food and Drug Administration and National Institute for Occupational Safety and Health. FDA and NIOSH Public Health Advisory. Explosions and fires in aluminum oxygen regulators. Washing Explosions and fires in aluminum oxygen regulators. Washington, DC: US Departm
Human Services, FDA, NIOSH, 1999.

2 National Institute for Occupational Safety and Health. Oxygen regulator flash severely burns one fire fighter-Florida, fire fighter fatality report $98 F-23$. Morgantown, WV: NIOSH, Division of Safety Research, 1999.

3 National Institute for Occupational Safety and Health. Emergency medical technician receives serious burns from an oxygen regulator flash fire-South Carolina, fire fighter fatality report 98F-24. Morgantown, WV: NIOSH, Division of Safety Research, 1999

4 National Institute for Occupational Safety and Health. Aluminum regulator fire injures one fire fighter-Nevada, fire
fighter fatality report $99 f-07$. Morgantown, WV: NIOSH, Division of Safety Research, 1999.

5 Allied HealthCare Products. Recall of LSP oxygen regulators. St Louis, MO: Allied HealthCare Products, 1999.

6 International Organization for Standardization. Pressure regulators and pressure regulators with flow-metering devices for medical gas systems. ISO 10524 . Geneva, Switzerland: ISO, medical
1995.

7 American Society for Testing and Materials. Standard test method for evaluating the ignition sensitivity and fault tolerance of oxygen regulators used for medical and emergency applications. PS 127. West Conshohocken, PA: ASTM, 2000.

8 Food and Drug Administration and National Institute for Occupational Safety and Health. FDA and NIOSH oxygen regulator video: hidden dangers. US Department of Health and Human Services, FDA, NIOSH. Washington, DC: 